\title{
An innovative multidisciplinary intervention to prevent and treat child obesity: the Epode Umbria Region OBesity Intervention Study (EUROBIS)
}

\author{
Roberto Pippi \\ roberto.pippi@unipg.it \\ C.U.R.I.A.Mo. Healthy Lifestyle Institute, University of Perugia, Perugia, Italy \\ Livia Buratta \\ livia.buratta@studenti.unipg.it \\ C.U.R.I.A.Mo. Healthy Lifestyle Institute, University of Perugia, Perugia, Italy
}

\begin{abstract}
The lifestyle's fundamental role in the approach to the young people with metabolic problems is now supported by the scientific evidence. However, multidisciplinary (including nutritional, physical activity and psychological aspects) intervention studies conducted on this issue are still lacking. This work aims to reflect on issues concerning the EUROBIS multidisciplinary intervention study, which aims to contrast childhood obesity, addressing the complex nutritional, motor, and psychological aspects to improve children's lifestyle through the implementation of curative and preventive strategies. The curative, clinical approach already proved to be effective in a significant reduction in body weight, BMI, waist circumference, fat mass, waist circumference/height index, and an improvement of Mediterranean diet adherence and physical activity measures, in subjects with overweight/obesity [1]. Now we present the first results of the preventive project "Let's improve the Umbrian children lifestyle", a school-based intervention, conducted in 2015-16 school year on first classes of primary schools in Umbria (more than 4000 children) resulting in an improvement in Mediterranean diet adherence and physical activity measures. This study confirms that multidisciplinary lifestyle intervention can improve anthropometric, nutritional and physical activity outcomes and represents the cornerstone to build recommendations with a high level of evidence within the Italian standards of care, although it has demonstrate the difficulties of young people and parents to join it.
\end{abstract}

\section{Introduction}

Social, cultural and cognitive factors are seems to be important determinants of people eating and physical activity habits linked with weight and health problems [2, 3]. The Mediterranean Diet, characterized by a high intake of vegetables, fruits, nuts, cereals, whole grains, and olive oil, as well as a moderate consumption of fish and poultry, and a low intake of sweets, red meat and dairy products, has been proved to be most sustainable and effective in terms of prevention of obesity-related diseases [4]. Weight gain and sedentariness [5] impact on the general health status and development of chronic non-communicable diseases (Noncommunicable Diseases, or NCDs, such as cardiovascular diseases, certain types of cancer, chronic respiratory diseases, obesity and diabetes) whose prevention is an international public health priority since childhood. For that reason, the scientific interest in healthy nutrition and physical activity $[6,7]$ in developmental age has grown. The evidence of effectiveness regarding the strategies and actions that 
governments, communities and families can put in place to prevent obesity need to be deepened in some aspects. There is strong evidence of the health consequences of poor nutrition and insufficient amount of movement, two of the most important determinants of NCDs. These, according to the WHO data, are responsible for 38 million people deaths every year, of which about 3.2 millions due to insufficient amount of physical activity [8]. Italy ranks among the countries with higher prevalence of negative determinants for young people health: official ministerial data [9] showed incorrect nutritional habits at meals, high sedentariness and insufficient physical activity. In such framework, evidence indicates that there is a need for multidisciplinary clinical and school-based actions, involving the family $[10,11]$. In the region of Umbria, Italy, in 2014, the Epode Umbria Region Obesity Intervention Study (E.U.R.OB.I.S.) [12] developed as multidisciplinary study project (including nutritional, physical activity and psychological aspects) aimed at counteract childhood obesity. This was the first project of the EPODE [13] European network that included both clinical and community intervention programmes. This paper aims to reflect on issues concerning the EUROBIS projects, a curative (clinical) plus preventive (community, school-based) intervention. Speculating that a multidisciplinary preventive (community) intervention ameliorates some health-related lifestyle variables, according to C.U.R.I.A.Mo. curative, clinical intervention previously conducted in EUROBIS, we present the first results of the schoolbased project "Let's improve the Umbrian children lifestyle".

\section{Methods}

Study design. EUROBIS is an Italian project addressed to children and families; it is based on the EPODE methodology. The latter is characterized by a positive approach (without any cultural or social stigma) in the obesity prevention and treatment, involving public and private stakeholders and the decision-makers in different sectors of society working on childhood obesity determinants [12]. EUROBIS provides for participation in healthy living habits experiences, adapted to the needs of all socio-economic groups., addressing the complex nutritional, motor, and psychological aspects to improve children's lifestyle through the implementation of curative and preventive strategies. The curative approach for subjects with overweight/obesity (C.U.R.I.A.Mo. multidisciplinary clinical intervention) are previously described in detail by Ranucci et al. (2017) [1], Mazzeschi et al. (2014) [12] and De Feo et al. (2011) [14]. Briefly, it included:

A Clinical examination of acceptance (with Paediatrician), for general anthropometric history and to exclude conditions contra-indicating the practice of exercise.

B Nutritional visit (with Nutritionist), to give the family healthy choices tools and to evaluate the Mediterranean Diet adherence.

C Cycles of recreational-motor (for children, lasting six months) and exercise (for adolescents, lasting three months) activities, supervised by a graduate in Motor Science, to promote the practice of physical activity and improve motor coordination and conditional skills. According to EUROBIS model [12], psychological counselling was also conducted, although it is not the object of this paper.

About preventive strategies, in EUROBIS, during the school year 2015/2016 was conducted the "Let's improve the Umbrian children lifestyle" project. It is a multidisciplinary community, school-based, preventive intervention $[10,11]$ that aimed at promoting healthy food choices, improve physical activity measures and awareness of the obesity determinants. It involved about 4600 six-year-old children of 383 primary schools in Umbria. The Project provided:

A Two hours/week of physical activity supervised by Sport Science Specialists at school;

B four meetings with nutritionists, psychologists, teachers and parents discussing healthy nutrition and childhood obesity determinants. 
Before attending the intervention, the parents of the participants gave their consent in writing. The study were carried out according to the Helsinki Declaration.

Measures. Before (T0) and at the end (T1) of interventions, the following parameters were evaluated:

A Anthropometric measures, such as body mass index (BMI), waist circumference (WC) and Waist-to-height Ratio index (WHTR). B. Mediterranean Diet Adherence measure, using the KIDMED questionnaire [15] and the score (KIDMEDS) obtained as follow: a -1 value is assigned to the questions that indicate a negative connotation and $a+1$ value to those with a positive aspect respect to the principles of the Mediterranean Diet. Score resulted from the sum of the values are classified into three levels: $\geq 8=0$ ptimal diet; 4-7=necessary improvement; $\leq 3=$ very low diet quality.

B Physical activity measures, as speed values (or $30 \mathrm{~m}$ sprint, evaluated through specific 30 metres speed test), muscular strength for the lower limbs strength (or Sargent, evaluated through the Sargent test). , and horizontal position flexibility (or HB, evaluated through Sit and reach test executed from a seated position) age-specific motor tests, as already described in detail by Ranucci et al. (2017) [1]. Finally, the levels of practiced physical activity (or PAQCS), was also evaluated through the PAQ-C Score, with values from 1 to 5, which result from the questionnaire PAQ-C [16]. Participation at project was evaluated, basing on sessions attendance.

Statistical analysis. Descriptive analysis of the sample was carried out (data shown as mean \pm standard deviation); the paired Student $t$ test was applied to compare all measurements before and after the intervention. Statistical significance was set at $\mathrm{p}<.05$. All analyses were performed with the statistical software SPSS version 21.0.

\section{Results}

Participation at treatment. The percentage of families who participated in the school project meetings with dietitians (19.1\%) and with psychologists (7.8\%) was low.

Anthropometric measures. BMI and WC increased ( $p<.001)$, while WHtR diminished $(\mathrm{p}<.001)$ after the intervention.

Mediterranean Diet measures. One percent more of families had consumed at least one meal/day with the parents. There was also an increase $(p=N S)$ in the percentage of respondents who had consumed at least four meals/week in the family; KIDMEDS tended to increase ( $p=N S$ ), detecting increased consumption of fruits, vegetables and fish.

Physical activity measures. Speed ( $\mathrm{p} \leq .001)$, lower limb strength ( $\mathrm{p} \leq .001)$, flexibility $(\mathrm{p} \leq .001)$ were increased, as well as physical activity levels ( $\mathrm{p} \leq .001)$.

All the results are reported in Table 1.

\section{Discussion}

Scientific evidence shows that a multidisciplinary approach, including at the same time nutritional and physical activity aspects, is the most effective strategy $[17,18,19]$ to counteract childhood obesity; it can provide better results than nutritional or physical activity interventions individually proposed[20]. Like the curative (clinical) approach, that it showed already proved to 
be effective in a significant reduction in body weight, BMI, waist circumference, fat mass, waist circumference/height index, and an improvement of Mediterranean diet adherence and physical activity measures, in subjects with overweight/obesity (Ranucci et al., 2017)[1], the results of the project Let's improve the Umbrian children lifestyle show encouraging signs of effectiveness in children anthropometric, Mediterranean Diet and physical activity measures. The project presented here are in line with evidence which stresses that family involvement $[21,22,23]$ and peer support, as the key to ensure greater adherence to treatments and promoting habits changes $[24,25]$. In fact, involving all the family members and providing for educational meetings in groups of people with the same age, the projects confirmed the good participation of young in the activities, against a lower participation of parents. The anthropometric and body composition results found in the Let's improve the Umbrian children lifestyle preventive intervention, are in line with those of C.U.R.I.A.Mo. clinical intervention and confirmed the results of other European and World projects [26]. In particular, the WHTR index showed an important downward trend which might predict association with reduced cardiovascular risk [27, 28]. According to ministerial data [9], in Italy, children eat fruit (41.3\%) and vegetables (36.9\%) once a day or never, engage in exercise only for one hour per day (23.5\%) or only for two hours in movement games $(20.1 \%)$ for week; finally, they spent more than two hours per day watching TV and playing with video games or using/mobiles (41.2\%). In the sample studied there was an encouraging improvement in healthy habits. In fact, after participation in the projects, children consumed more fruit, vegetables and fish, improved physical activity levels (PAQCS, p<.001) and physical activity measures (speed, strength and flexibility); at the same time, the percentage of children excessively (more than 5 hours/day) exposed to the use of TV and video games decreased $(-0.4 \%)$.

\section{Conclusions}

Overweight and obesity are a threat to children's health because they are associated with increased risk of chronic diseases. These diseases are determined by many factors of a different nature (organic, psychosocial and socio-environmental). For this reason, it is appropriate to implement multi-sector interventions with actions aimed at the various determinants such as unhealthy eating and sedentariness. Recent studies suggest that the problem also involve parents as mediators of children habits: therefore, the actions of the interventions must take care of the family variables. The project EUROBIS set up in 2014 in Umbria, that combined both preventive, community, and clinical intervention, addressed at families. The integration of different specialists' skills has proved effective, making the family feel the protagonist of their choices. Not all the families enrolled in the project, however, complete the entire program. Those who have joined in the full program, showed appreciable results, adopting the principles of the Mediterranean diet and understanding the importance of a regular practice of physical activity, attending to activities in peer groups. The project Let's improve the Umbrian children lifestyle is in line with the indications of WHO that identified the school as the gold standard setting for effective actions that involve families of children with overweight/obesity and made it possible to guarantee all participants at least two hours of physical activity per week. In addition, the project had a positive impact on the eating and physical activity habits of Umbrians families, sensitizing them towards the importance of movement and a healthy diet. The Eurobis interventions showed the difficulties related to the family's participation in the proposed programmes, underlining the need to continually understand and support the motivations of parents and children involved in health promotion actions. We intend to collect follow-up data with future studies (unfortunately the project, which included four years of observation, was suspended by the Umbria Region, contrary to what was initially foreseen by the 2014-2018 Regional Prevention Plan) to verify the maintenance or less than the results and possibly provide reinforcement cycles. Further studies will be needed to better investigate the contribution of these interventions in different populations age groups, with adequate sample sizes and control groups. In addition, it will be of interest to assess 
the applicability of the EUROBIS methodology to other conditions relevant to young people (e.g. malnutrition, eating disorders and psychological problems, bullying, school dropout), by involving other medical specialists. Finally, it is also necessary to achieve a conscious adherence to the indications and initiatives proposed, in a shared way, to put in place intersectoral strategies that exceed the concept of dietetic and exercise prescription (as for drugs).

Acknowledgments. I would like to thank Dr. Cristina Aiello, Dr. Claudia Ranucci, Prof.ssa Claudia Mazzeschi, Prof. Pierpaolo De Feo and Prof. Carmine Fanelli, of the University of Perugia, for their technical and scientific contributions.

\section{References}

[1] Ranucci C, Pippi R, Buratta L, Aiello C, Gianfredi V, Piana N, Reginato E, Tirimagni A, Chiodini E, Sbroma Tomaro E, Gili A, De Feo P, Fanelli C and Mazzeschi C. Effects of an Intensive Lifestyle Intervention to treat Overweight/Obese Children and Adolescents. BioMed Research International, 2017; Article ID 8573725: 1-11.

[2] Rozin P. Why We Know So Little About the Psychology of Eating in Humans. In: Meiselman H. (eds) Handbook of Eating and Drinking. Springer, Cham; 2020 pp 1557-1576.

[3] Gordon-Larsen P, Mcmurray RG, Popkin BM. Determinants of Adolescent Physical Activity and Inactivity Patterns. Pediatrics. 2000 Jun;105(6):E83. doi: 10.1542/peds.105.6.e83.

[4] Romagnolo DF, Selmin OI. Mediterranean Diet and Prevention of Chronic Diseases.Nutr. Today.2017;52:208-222

[5] Sartorio A, Marazzi N. Obesità infantile: Un problema "in crescita" (a rischio elevato di persistenza in età adulta). In: Clinica psicologica dell'obesità. Springer, Milano, 2012.

[6] Cena H, Calder PC. Defining a Healthy Diet: Evidence for The Role of Contemporary Dietary Patterns in Health and Disease. Nutrients. 2020; 12(2), 334.

[7] Kim J, Lim HJ. Nutritional Management in Childhood Obesity. J Obes Metab Syndr. 2019 Dec; 28(4): 225-235.

[8] Lim, S.S., Vos, T., Flaxman, A.D., Danaei, G., Shibuya, K. et al. A comparative risk assessment of burden of disease and injury attributable to 67 risk factors and risk factor clusters in 21 regions, 1990-2010: a systematic analysis for the Global Burden of Disease Study 2010. Lancet. 2012 Dec 15;380(9859):2224-60.

[9] Istituto Superiore di Sanità Surveillance system OKkio alla SALUTE: 2016 results. Edited by Paola Nardone, Angela Spinelli, Marta Buoncristiano, Laura Lauria, Daniela Pierannunzio e Daniela Galeone. 2018, XI, 83 p.

[10] Kelishadi R, Azizi-Soleiman F. Controlling childhood obesity: A systematic review on strategies and challenges. J Res Med Sci. 2014 Oct; 19(10): 993-1008.

[11] Lubans DR, Morgan PJ, Callister R, Collins CE, Plotnikoff RC. Exploring the mechanisms of physical activity and dietary behavior change in the program intervention for adolescents. J Adolesc Health. 2010 Jul;47(1):83-91.

[12] Mazzeschi C, Pazzagli C, Laghezza L, Battistini D, Reginato E, Perrone C, Ranucci C, Fatone C, Pippi R, Giaimo MD, Verrotti A, De Giorgi G, De Feo P. Description of the EUROBIS program: a combination of an Epode community-based and a clinical care intervention to improve the lifestyles of children and adolescents with overweight or obesity. Biomed Res Int. 2014;2014:546262. 
[13] Borys JM, Le Bodo Y, Jebb SA, Seidell JC, Summerbell C, Richard D, De Henauw S, Moreno LA, Romon M, Visscher TLS, Raffin S, Swinburn B. EPODE approach for childhood obesity prevention: methods, progress and international development. Obesity Reviews. 2012 ; Vol. 13, No. 4. pp. 299-315.

[14] De Feo P, Fatone C, Burani P, Piana N, Pazzagli C, Battistini D, Capezzali D, Pippi R, Chipi B, Mazzeschi C. An innovative model for changing the lifestyles of persons with obesity and/or type 2 diabetes mellitus. J Endocrinol Invest 2011, 34: e349-e354.

[15] Štefan L, Prosoli R, Juranko D, Čule M, Milinović I, Novak D, Sporiš G. The Reliability of the Mediterranean Diet Quality Index (KIDMED) Questionnaire. Nutrients. 2017 Apr 23;9(4). pii: E419.

[16] Gobbi E, Elliot C, Varnier M, Carraro. A Psychometric Properties of the Physical Activity Questionnaire for Older Children in Italy: Testing the Validity among a General and Clinical Pediatric Population. PLoS ONE 2016; 11(5): e0156354.

[17] Han JC, Lawlor DA, Kimm SY. Childhood obesity. Lancet 2010; 375: 1737-48.

[18] Ho M, Garnett SP, Baur L, Burrows T, Stewart L, Neve M, Collins C. Effectiveness of lifestyle interventions in child obesity: systematic review with metaanalysis. Pediatrics, 2012; 130 (6): e1647-e1671.

[19] Colquitt JL, Loveman E, O’Malley C, Azevedo LB, Mead E, Al-Khudairy L, Ells LJ, Metzendorf MI, Rees K. Diet, physical activity, and behavioral interventions for the treatment of overweight or obesity in preschool children up to the age of 6 years. Cochrane Database of Systematic Reviews 2016; 10(3):CD012105.

[20] Kumar S, Kelly AS. Review of childhood obesity: from epidemiology, etiology, and comorbidities to clinical assessment and treatment. Mayo Clin Proc. 2017;92(2):251-265.

[21] Bourke M, Whittaker PJ, Verma A. Are dietary interventions effective at increasing fruit and vegetable consumption among overweight children? a systematic review. Journal of Epidemiology and Community Health. 2014;68(5):485-490.

[22] Verjans-Janssen SRB, van de Kolk I, Van Kann DHH, Kremers SPJ, Gerards SMPL. Effectiveness of school-based physical activity and nutrition interventions with direct parental involvement on children's BMI and energy balance-related behaviors - A systematic review. PLoS One. 2018 Sep 27;13(9):e0204560.

[23] Rajmil L, Bel J, Clofent R, Cabezas C, Castell C, Espallargues M. Clinical interventions in overweight and obesity: a systematic literature review 2009-2014. Anales de Pediatria. 2016; 86(4):197-212.

[24] Sallis JF, Prochaska JJ, Taylor WC. A review of correlates of physical activity of children and adolescents. Medicin \& Science in Sports \& Exercise. Med Sci Sports Exerc. 2000 May;32(5):963-75.

[25] Golan M. Parents as agents of change in childhood obesity-From research to practice. International Journal of Pediatric Obesity 2006; 1(2):66-76

[26] Adom T, De Villiers A, Puoane T, Kengne AP. School-Based Interventions Targeting Nutrition and Physical Activity, and Body Weight Status of African Children: A Systematic Review. Nutrients. 2019 Dec 30;12(1). 
International Multidisciplinary Research Journal 2020, 10: 6-13 Special Issue on "Ricerca è Sviluppo 2020” Doi: 10.25081/imrj.2020.v10.6474

[27] Browning LM, Hsieh SD, Ashwell M. A systematic review of waist-to-height ratio as a screening tool for the prediction of cardiovascular disease and diabetes: 0.5 could be a suitable global boundary value. Nutr Res Rev, 2010; 23(2), 247-69.

[28] Tee JYH, Gan WY, Lim PY. Comparisons of body mass index, waist circumference, waistto-height ratio and a body shape index (ABSI) in predicting high blood pressure among Malaysian adolescents: a cross-sectional study. BMJ Open2020;10:e032874. 


\begin{tabular}{|c|c|c|c|c|c|c|}
\hline \multirow{2}{*}{ Variables } & \multicolumn{2}{|c|}{ T0 } & \multicolumn{2}{|c|}{ T1 } & \multirow{2}{*}{$t$} & \multirow{2}{*}{$\mathbf{p}$} \\
\hline & $M$ & $S D$ & $M$ & $S D$ & & \\
\hline \multicolumn{7}{|c|}{ Anthropometric measures } \\
\hline BMI $\left(\mathrm{kg} / \mathrm{m}^{2}\right)$ & 16,33 & 2,48 & 16,44 & 2,52 & $-8,13$ & .001 \\
\hline $\mathrm{WC}(\mathrm{cm})$ & 57,78 & 6,30 & 58,09 & 6,38 & $-5,11$ & .001 \\
\hline WHTR (cm) & 0,49 & 0,16 & 0,48 & 0.04 & 3,9 & .001 \\
\hline $\begin{array}{l}\text { Mediterranean Die } \\
\text { KIDMEDS }\end{array}$ & 6,26 & 2,15 & 6,31 & 2,10 & n.s. & n.s. \\
\hline \multicolumn{7}{|c|}{ Physical activity measures } \\
\hline $30 \mathrm{~m}$ sprint (s) & 8,03 & 2,25 & 7,16 & 1,18 & 25,65 & .001 \\
\hline Sargent $(\mathrm{cm})$ & 14,83 & 5,63 & 15,72 & 5,44 & $-8,53$ & .001 \\
\hline $\mathrm{HB}(\mathrm{cm})$ & 0,93 & 6,99 & 2,08 & 5,63 & $-10,32$ & .001 \\
\hline Physical activity le & & & & & & \\
\hline PAQCS & 2,61 & 0,53 & 2,74 & 0,57 & $-9,02$ & .001 \\
\hline
\end{tabular}

Note: Data are presented as mean (M) and Standard Deviation (SD). Statistical significance considered at $p<0.05$

Table 1: "Let's improve the Umbrian children lifestyle" results 